\title{
Failure Analysis and Quantitative Image Analysis of Leaded Brass Components
}

\author{
D.F. Susan, A.C. Kilgo, R.P. Grant, and G. Grimm \\ Sandia National Laboratories, Albuquerque, New Mexico
}

Fractures of leaded brass components were analyzed by scanning electron microscopy (SEM), light optical microscopy (LOM), and quantitative image analysis. Initial SEM observations suggested an abnormally high volume fraction of soft $\mathrm{Pb}$ phase in the material, but comparisons to optical image analysis on polished cross-sections showed that the composition was within requirements. Failure of leaded brass illustrates a good example of differences between ductile fractographic features and the bulk microstructure of a material and the importance of employing multiple analysis techniques.

Figure 1 shows backscatter SEM photomicrographs of the fracture surface of leaded brass (Alloy C36000: 61.5 wt.\% Cu, 35.5 wt.\% $\mathrm{Zn}$, and $3 \mathrm{wt} . \% \mathrm{~Pb}$ ). If the $\mathrm{Pb}$ concentration is measured by energy dispersive spectroscopy (EDS) of the fracture (not recommended) or by image analysis of the fracture surface (also not recommended), approximately $25 \% \mathrm{~Pb}$ is found. However, as shown in Fig. 2, the material contains only about 2 vol. $\% \mathrm{~Pb}$ which is consistent with the expected $\mathrm{Pb}$ concentration of the alloy. There are two reasons for the dramatic difference between the fracture surface and the bulk material. First, the fracture occurs preferentially through the $\mathrm{Pb}$ phase. Each soft $\mathrm{Pb}$ particle nucleates a microvoid and the voids link up to connect nearby $\mathrm{Pb}$ particles as the fracture progresses. And second, as the ductile microvoids grow the soft $\mathrm{Pb}$ phase is stretched across the inside of the voids as shown by arrows in Fig. 1b. The enhanced straining of the Pb phase results in a thin film of $\mathrm{Pb}$ across many of the microvoids and a much higher surface area fraction than volume fraction within the material. The effect is prevalent in bending failures as well -- the $\mathrm{Pb}$ is essentially smeared across the elongated dimple rupture fracture surface, Fig. 3.

Table 1 displays the results of quantitative analyses of $\mathrm{Pb}$ content using SEM/EDS and optical image analysis on the fracture surface and in the bulk. The results emphasize the fact that, while the amount of $\mathrm{Pb}$ measured from the fracture surface is valid for the final fracture condition, it could result in incorrect interpretation of the cause of failure if the bulk microstructure is not understood. When analyzing failures in multi-phase materials, it is important to obtain multiple views of the microstructure with complementary methods and to understand the unique characteristics resulting from the fracture process.

Table 1. Comparison of $\mathrm{Pb}$ content measured with multiple methods.

\begin{tabular}{|l|l|l|}
\hline Sample & Analysis method & Measured Pb content \\
\hline Fracture surface & SEM/EDS & $\sim 25 \mathrm{wt} . \% \mathrm{~Pb}$ \\
\hline Fracture surface & Image analysis & $18.1+/-1.5 \%$ (projected area $)$ \\
\hline Polished section & SEM/EDS $(15 \mathrm{kV})$ & $1.86+/-0.11 \mathrm{wt} . \% \mathrm{~Pb}$ \\
\hline Polished section & Image analysis $(10$ images, $200 \mathrm{X})$ & $2.03+/-0.16$ vol. $\%(\sim 2.8$ wt. $\% \mathrm{~Pb})$ \\
\hline
\end{tabular}

${ }^{*}$ Sandia National Laboratories is a multi-program laboratory managed and operated by Sandia Corporation, a wholly owned subsidiary Lockheed Martin Corporation, for the U.S. Department of Energy's National Nuclear Security Administration under contract DE-AC04-94AL85000. 

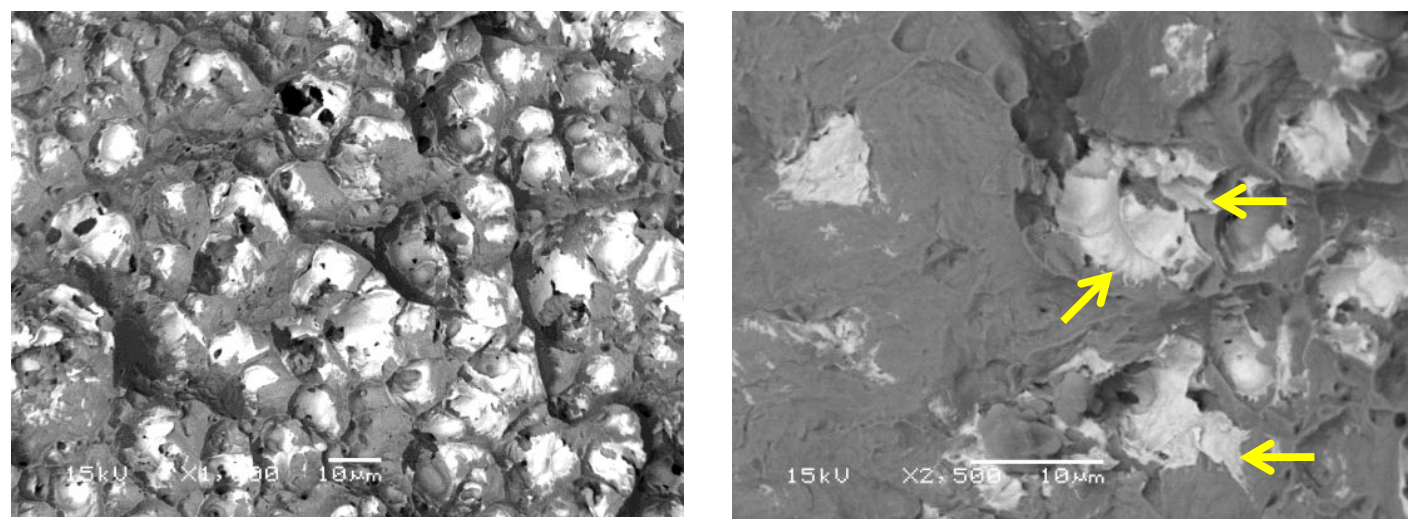

Fig. 1. Backscatter SEM photomicrographs showing high amount of $\mathrm{Pb}$ (bright phase) on the fracture surface due to the formation of thin $\mathrm{Pb}$ films during straining.
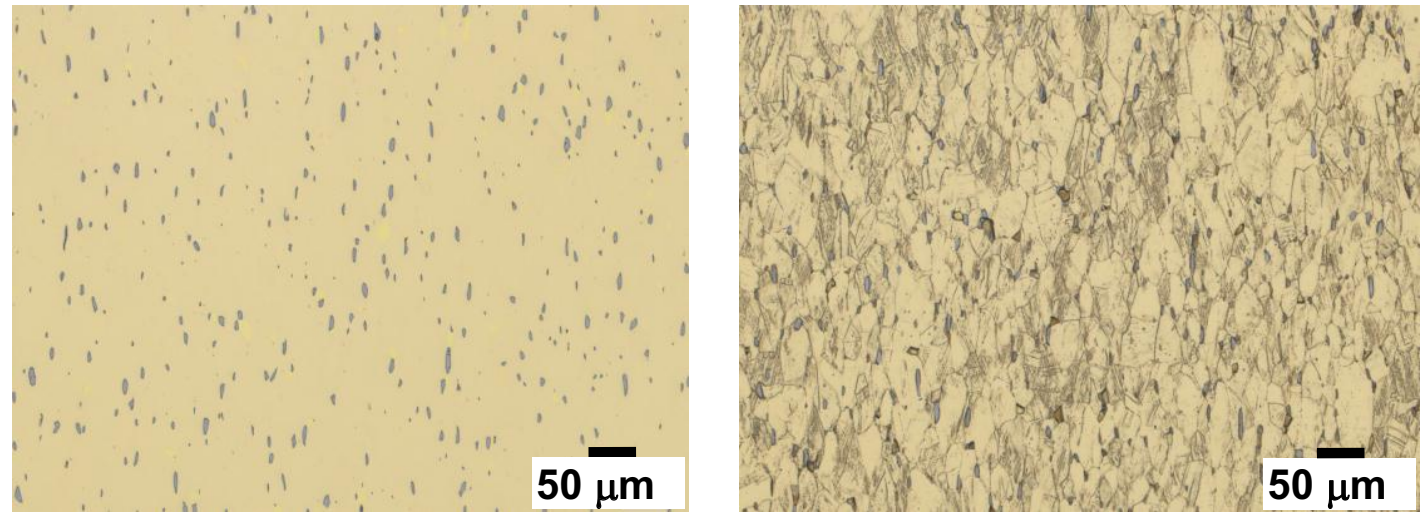

Fig. 2. Color light optical photomicrographs of $\mathrm{Pb}$ particles distributed in the brass matrix. (left) as polished, (right) etched to show deformed grain structure, "half-hard" condition.
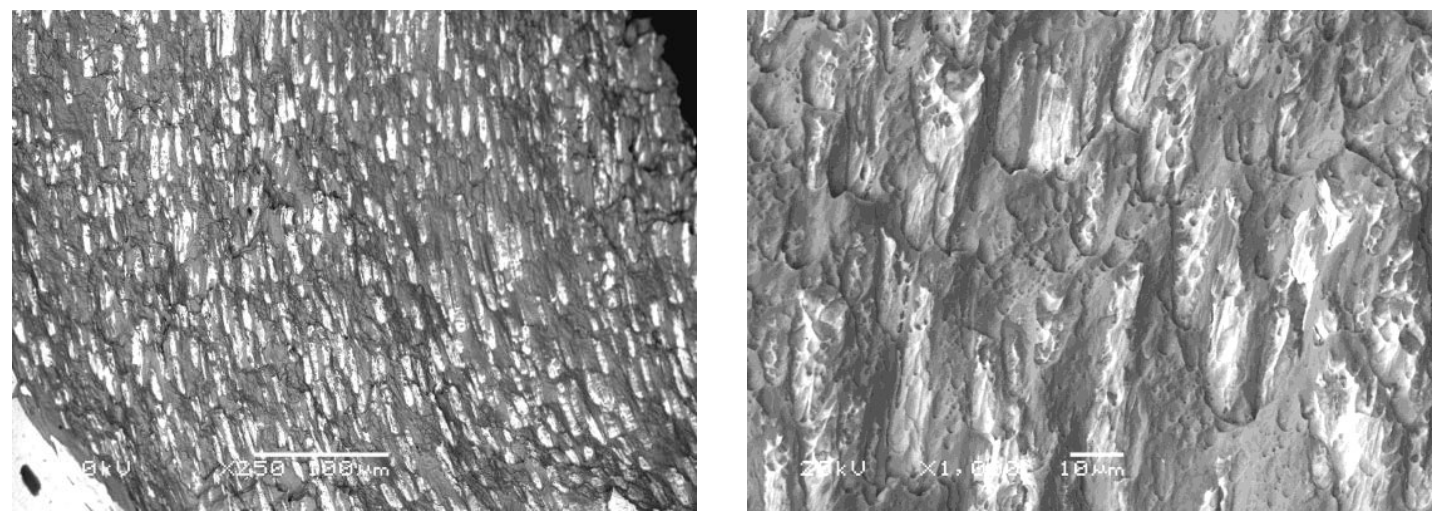

Fig. 3. Backscatter SEM images of bending fractures of free-cutting leaded brass. The $\mathrm{Pb}$ particles are smeared across the "elongated dimple rupture" surface. 